\title{
IMPROVING THE ORGANIZATIONAL CITIZENSHIP BEHAVIOR (OCB) THROUGH DEVELOPING EFFECTIVE INTERPERSONAL COMMUNICATION AND TRANSFORMATIONAL LEADERSHIP
}

\author{
Herfina $^{\left.a^{*}\right)}$, Dian Wulandari ${ }^{a)}$ \\ a) Pakuan University, Bogor, Indonesia \\ *) Corresponding Author: herfina.unpak@gmail.com
}

Article history: received 20 August 2019; revised 31 August 2019; accepted 16 September 2019

\begin{abstract}
The teacher's Organizational Citizenship Behaviour (OCB) become an important factor that involve in the teaching process at school. Unfortunately, based on the preliminary survey at several Junior High-School in Bogor, it had been found that many teachers had low-level of OCB. In addition, it had been found that teachers had ineffective interpersonal communication and had received less transformational leadership. Based on that issue, we formulated the objectives of this research as to improve the teachers' OCB through developing effective interpersonal communication and transformational leadership. This research was carried out at 266 teachers from 20 Junior High-Schools, in Bogor. This research was used correlational technique to assess the degree of relationship among those variables. The findings of this research can be summarized that there is a positive and significant correlation (1) between interpersonal communication with OCB $(r=0.604, p<0.01)$, (2) transformational leadership with OCB $(r=0.602$, $p<0.01)$, and between interpersonal communication and transformational leadership simultaneously with $\mathrm{OCB}(\mathrm{r}=0.613, \mathrm{p}<0.01)$. These findings supported the recommendations to improve OCB through developing teachers' interpersonal communication effectiveness and school principals' transformational leadership.
\end{abstract}

Keywords: organizational citizenship behaviour; interpersonal communication: transformational leadership

\section{INTRODUCTION}

Law of the Republic of Indonesia Number 14 of 2005 on Teachers and Lecturers mentions that teachers and lecturers hold a very strategic function, role, and position in human development in the field of education in a country. A professional teacher requires a number of requirements such as qualified education, task responsibility, professional job behaviour, and others, in the situation and the conditions expected from the profession. It is very important that the teacher has willingness to show behaviour of exceeding the duty of teachers known as Organizational Citizenship Behaviour (OCB). However, preliminary survey results obtained from 30 teachers from several Bogor City Junior High School showed indications that most teachers did not optimally engaged in activities within their organization providing initial assumption that OCB among school teachers in Bogor City is still low. Most teachers tend not to optimally involve in activities both inside and outside of school. The tasks carried out is still limited to meeting the required formal job description. The preliminary survey results also indicate that many factors could affect teacher's OCB, among them were principal's transformational leadership and teacher's interpersonal communication. As such condition this research would like to study some variables related to Organizational Citizenship Behaviour (OCB) in terms of principals' transformational leadership and interpersonal communication effectiveness among teachers and principals. Based on the literature review and evidence from prior researches above mentioned, it can be stated research hypotheses as follows:

a. There is a positive relationsip between transformational leadership with OCB b. There is a positive relationship between interpersonal communication with OCB.

There is a positive relationship between transformational leadership and interpersonal communication simultaneously with OCB.

\section{Organizational Citizenship behaviour (OCB)}

Organ et. al., conceptualized OCB into five dimensions, namely, conscientiousness, sportsmanship, courtesy, civic virtue, and altruism. In explanation of these variables, he noticed that - Conscientiousness is a discretionary behaviour of employees that exceed the minimum role requirements in organization [1]. Sportsmanship refers to the willingness of employees to tolerant less ideal circumstances without complaining. Courtesy is another shape of discretionary behaviour that prevents work-related problems with other employees. The person who shows - Civic Virtue, participate responsibly in, is involved in, or is concerned about the life of the company. Finally, - Altruism is a discretionary behaviour of helping others in organizationally related task or problem.

Colquitt, Lepine and Wesson defined OCB as voluntary employee activities that may or may not be rewarded but that contribute to the organization by improving the overall quality of the setting in which work takes place [2]. The first category of citizenship behaviour is the one with which you're most likely to be familiar: Interpersonal Citizenship Behavior. Such behaviors benefit co-workers and colleagues and involve assisting, supporting, and developing other organizational members in a way that goes beyond normal job expectations. For example, Helping involves assisting co-workers who have heavy workloads, aiding them with personal matters, and showing new 
employees the ropes when they first arrive on the job. Courtesy refers to keeping co-workers informed about matters that are relevant to them. Sportsmanship involves maintaining a good attitude with co-workers, even when they've done something annoying or when the unit is going through tough times. The second category of citizenship behaviour is Organizational Citizenship Behaviour. These behaviours benefit the larger organization by supporting and defending the company, working to improve its operations, and being especially loyal to it. For example, Voice involves speaking up and offering constructive suggestions for change. Civic Virtue refers to participating in the company's operations at a deeper-than-normal level by attending voluntary meetings and functions, reading and keeping up with organizational announcements, and keeping abreast of business news that affects the company. Boosterism means representing the organization in a positive way when out in public, away from the office, and away from work.

\section{Transformational Leadership}

The concept of transformational leadership was initially introduced by Burns that is, changing leadership process between leaders and subordinates to help each other to advance to a higher level that is guided by the spirit and motivation [3]. Then, Bass expanded upon Burns' original ideas to develop what is today referred to as Bass' Transformational Leadership Theory [4]. According to Bass, transformational leadership can be defined based on the impact that it has on followers. Transformational leaders, Bass suggested, garner trust, respect, and admiration from their followers. According to Bass, there are four components of transformational leadership, namely: 1) Intellectual Stimulation - Transformational leaders not only challenge the status quo; they also encourage creativity among followers. 2) Individualized Consideration - Transformational leadership also involves offering support and encouragement to individual followers. 3) Inspirational Motivation Transformational leaders have a clear vision that they are able to articulate to followers. 4) Idealized Influence - The transformational leader serve as a role model for followers [4]. Luthans defined transformational leadership is more on leader's shifting the values, beliefs, and needs of their followers. Transformational leaders characterized by idealized leadership, inspiring leadership, intellectual stimulation, and individualized consideration. Lee Kim Lian and Low Guan Tui conducted a research on OCB, and they generalized a conclusion that transformational leadership had a strong relationship with OCB $(r=0.63, p<0.01)$ [5].

\section{International Communication}

Interpersonal communication involves a direct verbal or nonverbal interaction between two or more active participants. Interpersonal communication can take many forms, both formal and informal, and be channeled through numerous media and technologies [6]. Hellriegel and Slocum defined interpersonal communication is the pattern of communication flows, relationships, and understandings developed over time among people, rather than focusing on the individual and whether a specific message is received as intended by the sender [7]. This pattern involve the ongoing flow of verbal, written, and nonverbal messages between two people or between one person and others. Communication channels can influence the likelihood of a match between messages as sent and as actually received and interpreted. The more accurately the message moves through the channel, the more clearly the receiver will understand it. Gibson et. al., defined interpersonal communication Communications as flow or exchange information between individuals in face-to-face and group situations [8]. Interpersonal communication satisfaction in work environment is positively related to OCB. However, the main motive of the relationship between communication satisfaction and OCB is prescribed in the social exchange theory. This theory argues that people reciprocate the advantages that they receive from their organization [9]

\section{RESEARCH METHODS}

This study applies correlational method and used the questionnaires as intruments for data collecting. Descriptive statistics and quantitative analysis are used for finding initial solution to the problem encountered. The entity of this study were 793 public school teachers spreading out in 20 (twenty) junior highs in Bogor, West Java Indonesia. By using formula of Taro Yamane 266 teachers were taken as sampling unit. The normality assumption is prerequisites to proceed to further test calculated with Lilliefors' formula. Analysis is conducted with multiple linear regression and hypothesis testing is performed at a significance level of 0.05 using Product-Moment Coefficient of Correlation.

\section{RESULTS AND DISCUSSION}

\section{A. Transformational Leadership and $O C B$}

Hypothesis testing confirms that transformational leadership has a positive relationship with OCB, with correlation coefficient value of 0.602 and the coefficient of determination $=0.362$. This means that $36.2 \%$ of OCB is determined by transformational leadership, while the other $63.8 \%$ is contributed by other variables. This finding indicates that with transformational leadership, principal of the school can develop this competence to influence, change, motivate, and become a role model for member of organization, as well as to make the right decisions and to develop the organization into a better direction for the present and the future in order job satisfaction and commitment are raised to a higher level of morality and the organization concern is given priority ahead of personal interest.

\section{B. Interpersonal Communication and $O C B$}

Interpersonal Communication had a positive relationship with $\mathrm{OCB}$, with correlation coefficient value of 0.604 and the coefficient of determination $=0.365$. This shows that $36.5 \%$ of OCB is determined by interpersonal communication, while the other $63.5 \%$ is contributed by other variables. This finding indicates that interpersonal communication is the delivery of messages and the exchange of direct and face to face information between individuals as 
well as to generate feedback to make the message understood and be conveyed properly. Interpersonal communication is one factor that can be improved so that teachers can optimize their function in carrying out their duties to achieve the best educational purpose. Thereby increasing teacher interpersonal communication will lead to the higher level of OCB in school.

\section{Transformational Leadership, Interpersonal Commnication and $O C B$}

The hypothesis testing results show that there is a significant relationship between transformational leadership and interpersonal communication simultaneously to OCB, with correlation of coefficient values $=0.613$ and the coefficient of determination $=0.3759$. This means that only $37.59 \%$ of OCB is caused by transformational leadership and interpersonal communication while at $62.41 \%$ is contributed by other variables not included in the model

\section{CONCLUSION}

The The research findings showed that there were positive and significant relationship between the transformational leadership, and interpersonal communication with OCB. Based on the initial design of the constellation between variables, the results showed that the contribution of transformational leadership variable on OCB was $36.2 \%$ and interpersonal communication was $36.5 \%$ indicating the moderate contribution to the teachers' OCB. When combined together, contribution of the transformational leadership and interpersonal communication reaches $37.59 \%$ indicating the contribution of other variables not included in the model to predict on OCB are $62.41 \%$ confirming this model is of moderate goodness. Other researchers wishing to conduct similar studies may include other variables such as; teacher's professional commitment, achievement motivation, work culture of teachers, teachers' resilience, creativity, work experience, teacher's training, decision-making techniques and so forth

\section{REFERENCES}

[1] Organ, Dennis W., Philip M. Podsakoff, and Nathan P. Podsakoff. 2011. Expanding the criterion domain to include organizational citizenship behavior: Implications for employee selection. Journal of Management, 3 (2), pp. .281-323, 2011.

[2] Colquitt, J.A., J.A. Lepine, and M.J. Wesson. Organizational Behavior: Improving Performance and Commitment in the Workplace. New York: McGrawHill. 2015.

[3] Burns, James M. Leadership. N.Y: Harper and Raw. 2007.

[4] Bass, Benard M. Leadership and Performance. New York: Free Press. 2008.

[5] Kim Lian and Low Guan Tui. Leadership Styles and Organizational Citizenship Behavior: The Mediating
Effect of Subordinates' Competence and Downward Influence Tactics. Journal of Applied Business and Economics, 13 (2), pp. 59-96.2012.

[6] Hitt, M.A., C.C. Miller, and A. Colella. 2011. Organizational Behavior. Hoboken, NJ: John Wily \& Sons. 2011.

[7] Hellriegel, Don., and J.W. Slocum, Jr. Organizational Behavior. Mason, OH: South-Westrn, Cengage Learning. 2011.

[8] Gibson, J.L., J.M. Ivancevich, J.H. Donnelly, Jr., and R. Konopaske. Organizations: Behavior, Structure and Processes. New York: McGraw-Hill. 2012.

[9] Kandlousi, Nader Sheykh Al Eslami, Anees Janee Ali, and Anahita Abdollahi. "Organizational citizenship behavior in concern of communication satisfaction: The role of the formal and informal communication." International Journal of Business and Management 5, no. 10, pp 51-59. 2010. 